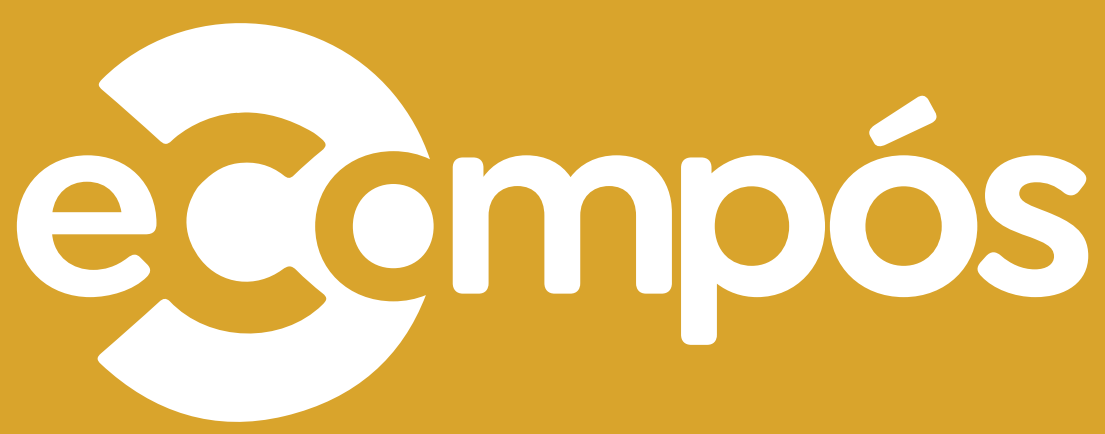

Revista da Associação Nacional dos Programas de Pós-Graduação em Comunicação

ISSN 1808-2599, v. 24, jan-dez,

publicação contínua, 2021, p. 1-20.

doi.org/10.30962/ec.2375

\title{
Juntas e
}

misturadas no

GNT? Performances

de feminilidades

sob tensão

JULIANA FREIRE GUTMANN

Universidade Federal da Bahia, Salvador, Bahia, Brasil

\section{TESS CHAMUSCA}

Universidade Federal da Bahia, Salvador, Bahia, Brasil

\section{ID 2375}

Recebido em

29/12/2020

Aceito em

13/06/2021 


\section{/ resumo}

No âmbito dos estudos de TV, discute-se relações entre performances de gênero e de marca. $\mathrm{O}$ artigo problematiza construções de feminilidades que respondem por estratégias comunicacionais do GNT, tendo a noção de performance como categoria teórico- metodológica para análise de como e com quais corpos o canal constitui figurações de si. Para tanto, contempla sua formação histórica e analisa um corpus formado por seis produtos - veiculados na programação, no site, no YouTube e Facebook - referentes ao Dia Internacional da Mulher, em 2017, quando são evidenciadas aproximações com o sentido de diversidade. Resultados indicam ambiguidades em como o canal se faz ver, desde então, nessas ambiências.

Palavras-chave: Feminilidades. Performance. Audiovisual. GNT.

\section{Juntas y mezcladas en GNT? Performances de feminidades bajo tensión}

En el ámbito de los estudios de televisión, se analizan las relaciones entre género y actuaciones de marca. El artículo discute construcciones de feminidades que responden a las estrategias comunicacionales de GNT basadas en la noción de performance como categoría teórico-metodológica para el análisis de cómo y con qué cuerpos el canal constituye figuraciones de sí mismo. Para tanto, contempla la formación histórica del canal y analiza un corpus conformado por seis productos -transmitidos en el programa, en el sitio web, en YouTube y Facebook- en referencia al Día Internacional de la Mujer, en 2017, cuando aproximaciones con sentido de diversidad se evidencian. Los resultados indican ambigüedades en cómo se ha visto el canal, desde entonces, en estos ámbitos.

Palabras clave: Feminidades. Performance. Audiovisual. GNT.Mediatización. Circulación. Comunicación.

\section{Are we blended on GNT? Performances of femininities under tension}

Within the scope of TV studies, this article discusses the relations between gender and brand performances. It problematizes constructions of femininities that respond to the communication strategies of the GNT channel based on the notion of performance as a theoretical-methodological category for analyzing how and with which bodies the channel constitutes figurations of itself. Therefore, it is considered the historical formation of the channel in order to analyze a corpus made up of six products - broadcast on the program, on the website, on YouTube and Facebook - referring to the International Women's Day, in 2017, when approximations with a sense of diversity are evidenced. Results indicate ambiguities in how the channel has been seen, since then, in these ambiences.

Keywords: Femininities. Performance.

Audiovisual. GNT.Mediatization. Circulation. Communication. 


\section{/ autores}

\section{ecompós}

\section{Juliana Freire GUTMANN}

Doutora pelo Programa de Pós-Graduação em Comunicação e Cultura da Universidade Federal da Bahia. Professora da Faculdade de Comunicação e do Programa de Pósgraduação em Comunicação e Cultura Contemporâneas da Universidade Federal da Bahia da UFBA. Coordena o Grupo de Pesquisa Cultura Audiovisual, Historicidades e Sensibilidades (CHAOS) e é pesquisadora docente do Centro de Pesquisa em Estudos Culturais e Transformações na Comunicação (TRACC).

Universidade Federal da Bahia, Salvador, Bahia, Brasil.

E-mail: jugutmann@gmail.com

\section{ORCID}

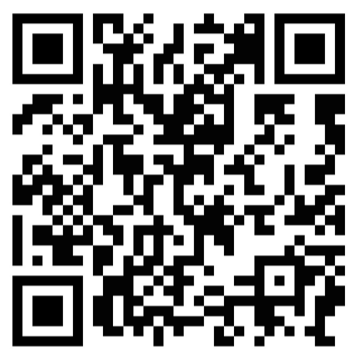

\section{Tess CHAMUSCA}

Doutora pelo Programa de Pós-Graduação em Comunicação e Cultura Contemporâneas da Universidade Federal da Bahia. Pesquisadora associada ao Centro de Pesquisa em Estudos Culturais e Transformações na Comunicação (TRACC) e ao Grupo de Pesquisa Cultura Audiovisual, Historicidades e Sensibilidades (CHAOS).

Universidade Federal da Bahia, Salvador, Bahia, Brasil.

E-mail: tesschamusca@gmail.com

\section{ORCID}

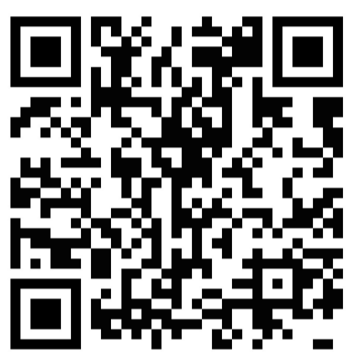




\section{Introdução}

O canal pago brasileiro GNT, sigla originalmente criada para Globosat News Television, surge em 1991 com programação centrada em notícias e documentários estrangeiros. Quando a Globosat lança a Globo News, em 1996, o GNT passa a constituir prestígio pela associação da sua marca a produções documentais independentes nacionais. O sentido de segmentação dedicado a um determinado público feminino, associado a moda, beleza, culinária e comportamento, só se institucionaliza a partir dos anos 2000, com programas como Superbonita e Saia Justa. Historicamente, o GNT construiu sentidos de feminilidades assentados em corpos da mulher cis, ocidental, branca, magra, jovem, urbana, que é mãe e/ou profissional bem-sucedida (CHAMUSCA, 2020; MACHADO; 2013; PONTE, 2009).

Nos últimos anos, antenado com a agenda feminista, o GNT tem apostado em pautas sobre o combate à desigualdade de gênero, mas com poucas desestabilizações em relação a esse corpo midiático hegemônico. Chamou-nos atenção, enquanto marco de uma possível ruptura, as ações para o Dia Internacional da Mulher de 2017, que coincide com o período de lançamento da programação daquele ano. É nesse momento que localizamos uma intenção mais enfática de articulação com perspectivas outras do corpo feminino, que traz à tona ambiguidades entre a atuação do canal na grade de programação e nas redes sociais digitais.

Em 2017, no Dia Internacional da Mulher, o canal realiza a ação \#PoderdasMinas na Avenida Paulista, em São Paulo-SP, uma batalha de rap com as cantoras Drik Barbosa, Mariana Mello, Nikki e Slick, que teve como juíza a cantora fluminense MC Carol, cuja visibilidade nos espaços digitais se associa ao ativismo feminista no funk. Seu corpo tensiona o estereótipo da cantora diva pop. É negra, gorda, favelada e sem papas na língua. $O$ evento foi conduzido pela rapper Gabi Nyarai, mulher periférica que refuta os códigos de feminilidade performados cotidianamente nos programas televisivos por meio da forma de se vestir e de seu gestual. A batalha teve transmissão ao vivo pela página do GNT no Facebook ${ }^{1}$ e vídeo divulgado no seu canal no YouTube².

Essa ação motivou as perguntas que movem o estudo aqui apresentado ${ }^{3}$. Quais disputas sobre construções de feminilidades atravessam o GNT no seu processo de formação enquanto canal televisivo e como isso transborda para as ambiências digitais? Como construções de feminilidades do GNT auxiliam a compreender sua performance televisiva, ou seja, seu modo próprio de performar sujeitos e papéis no processo comunicativo? Como, na campanha para o Dia Internacional da Mulher, o canal se articula a uma determinada construção midiática de feminilidade agora tensionada por outros corpos nas redes sociais digitais? O que esta análise permite projetar sobre construções futuras do canal? Nossa hipótese é de que a constituição de performances do feminino do GNT, atualizadas pelo feminismo, faz ver contradições nas figurações de mulher que atravessam a programação, o site e as redes sociais digitais.

As ambiguidades que perpassam esse processo se articulam às reflexões de Néstor García Canclini $(2009,2015)$, para quem indivíduos e grupos são constituídos pela heterogeneidade, a partir de circuitos desiguais de produção e apropriação da cultura, marcados por conflitos e coexistências. 0 autor traz em causa que a diversidade, um valor importante para o GNT no período analisado, "não se apresenta somente porque distintos setores da sociedade escolhem se desenvolver de formas diferentes, mas também porque tiveram oportunidades desiguais de acesso aos bens" (CANCLINI, 2009, p. 145). Diante de tal complexidade, estamos interessadas tanto quanto o autor em problematizar que tipo de televisão pode narrar "a

1 https://www.facebook.com/gnt/. Acesso em 15 de Jan. 2019.

2 https://www.youtube.com/channel/UCof866RMRdL5mSVnipiOHxg. Acesso em 15 de Jan. 2019.

3 Fruto de pesquisas com financiamento do CNPq e da Capes. 
heterogeneidade e a coexistência de vários códigos em um mesmo grupo e até em um mesmo indivíduo" (CANCLINI, 2015, p. 136).

Do ponto de vista teórico-metodológico, a contribuição proposta para o campo dos estudos televisivos opera num duplo movimento. Por um lado, buscamos explorar a noção de performance para a análise das estratégias comunicativas de um canal; por outro, e de maneira articulada, pretendemos operar essa mesma dimensão para a análise de como e com quais corpos (num sentido também performático) o GNT se relaciona para a constituição de sua identidade. Em um sentido mais amplo, o artigo busca contribuir para a discussão sobre os lugares midiáticos construídos para a mulher na atualidade e como essas posições são tensionadas na grade televisiva e nas ambiências digitais.

Ressaltamos ainda que o debate sobre as feminilidades hegemônicas no GNT e seus tensionamentos é realizado aqui tendo como fundamento uma concepção de gênero que o considera uma "repetição estilizada de atos". Por meio dela, as normas de gênero, organizadas a partir de uma continuidade entre sexo, gênero, desejo e prática sexual, ao mesmo tempo se materializam - inclusive por meio de instituições como um canal televisivo - e se mostram historicamente revisáveis (BUTLER, 2003).

Para desenvolver uma análise pertinente ao espaço de um artigo com material suficiente para responder às perguntas propostas, utilizamos certos critérios de seleção do corpus. Sobre a atuação do canal na internet, foi realizada uma busca por conteúdos vinculados à semana do Dia Internacional da Mulher, publicados entre 1o e 11 de março de 2017. Foram selecionados o vídeo promocional da ação \#PoderdasMinas, publicado no canal do GNT no YouTube, a transmissão ao vivo dessa ação no Facebook, um vídeo institucional sobre a efeméride, também divulgado na página da emissora no Facebook, e a divulgação, pelo site institucional, da nova programação de 2017. Do que foi exibido na grade, selecionamos o episódio do Saia Justa do Dia Internacional da Mulher e a vinheta sobre a programação do GNT.Doc para o Mês da Mulher.

Ainda que não circunscritos a esse corpus, reportagens, depoimentos de realizadores, vinhetas, campanhas e trechos do brand book foram acessados para rastrear parte do processo de formação do canal. Esse investimento não pretende dar conta da história do GNT, mas se mostrou valioso para a compreensão das continuidades e rupturas que nos fazem reconhecer particularidades do canal e suas relações com feminilidades. Nessa mesma perspectiva, a análise das ações de 2017 permitiu observar esse movimento naquilo que se confirmou, nos anos seguintes, como tendência.

\section{Performances como indícios da experiência com o canal televisivo}

Neste artigo, testamos um duplo e articulado uso do conceito de performance para a análise de como o GNT constitui figurações do corpo feminino em distintos contextos midiáticos. Avançamos em contribuições anteriores de Gutmann (2015), que se apropria da noção de performance para a compreensão da identidade de um canal. Ao dar relevo à experiência televisiva, a autora busca na performance um caminho para apreender estratégias de interação que nos fazem reconhecer formas específicas de uma emissora. Por um viés estético-cultural, sustenta que aquilo comumente identificado como "marca" não se reduz a uma estratégia produtiva, mas é resultado do jogo de interações entre lógicas produtivas e mercadológicas, modos de recepção, contextos midiáticos, identitários etc. e as formas expressivas de um canal, que incluem programas, vinhetas, apresentadores e seus espalhamentos nas ambiências digitais. 0 GNT é, assim, entendido como espaço de experiência que evoca e institui expectativas de consumo.

Reconhecendo a importância das pesquisas com foco no campo da produção, bem como as que priorizam análises textuais das vinhetas para a compreensão do "específico" de um canal, propomos uma mirada para os arranjos e rearranjos de sentido que tenham o corpo dos mediadores e mediadoras como 
dimensão analítica. A atuação de corpos midiáticos que habitam e orbitam um canal, conformada por determinados padrões, nos parece central para a compreensão de seus modos de reconhecimento pela audiência. Esses corpos constituem figurações da emissora e muito nos dizem sobre suas estratégias comunicativas. Nesse sentido, a performance é acionada por este estudo como dimensão de análise do corpo construído para "a mulher" do e no GNT.

Erving Goffman foi um dos primeiros estudiosos a apontar para a Comunicação a força da noção de performance social. Com o sentido de metáfora teatral, Goffman (2002) destacou o jogo de papéis, sistematizados por uma dada tradição cultural (os quadros sociais), pelos quais os sujeitos atuam nas diferentes relações e situações. Zumthor (2007), no campo da poesia oral, ao investir nas possibilidades de um corpo performático atuante na experiência de consumo, ressalta a potência desestabilizadora da dimensão reiterada da performance, uma vez que são pelos usos que as formas adquirem sentidos.

Schechner (2006) amadurece essa abordagem. Ao conceber performance como um "mostrar fazer", o autor sustenta que esta pode ser pensada para toda atividade humana e elabora a noção de comportamentos restaurados (restored behaviors) como chave metodológica de análise. Para ele, performances são ações para as quais as pessoas ensaiam, são práticas que constituem identidades, narrativas, rituais e convenções. Inspirada nesse argumento, Taylor (2013) entende performance como dimensão tangível de acesso a memórias, conhecimentos e identidades que se dá a partir de processos de incorporações.

O sentido de processo marca o entendimento de ambos os autores sobre performance e nos habilita a convocar relações com o caráter cultural dessa experiência.

Se performance constitui sentidos através de práticas repetidas e culturalmente reconhecidas, Schechner reconhece que eventos, ações ou comportamentos podem ser examinados 'como' performance justamente porque estão, sempre, em processo (GUTMANN, 2015, p. 5).

A noção de formação e a ênfase às noções de convenção são centrais no trabalho de Raymond Williams (1979), para quem a análise cultural deve considerar transformações das formas materiais dos modos de pensar. Por essa acepção, afirmamos que o GNT constitui performances pelas quais operam formas hegemônicas de feminilidades e de masculinidades, a partir de certos padrões que reiteram formas e silenciam outras num determinado tempo-espaço. É pela identificação desses padrões que podemos detectar transformações e tendências.

Apostar na noção de performance para compreender o modo como o GNT se faz ver pressupõe reconhecer formas e processos históricos potencialmente historicizados e permanentemente restaurados. A identidade de um canal não está localizada "no presente", mas demanda, a quem analisa, esforço de historização que a considere enquanto processo. Como afirmam Cardoso Filho e Gutmann (2019), o movimento articulado entre restauração/reconhecimento e ruptura/estranhamento só é possível porque a performance não pode ser vista em um objeto específico e isolado no tempo. Ela se dá no nível da relação.

Buscamos analisar os lugares de feminilidades construídos pelo GNT com base na observação dos corpos que ali transitam e que constituem espaços de interação. Temos, assim, a abordagem da performance direcionada à observação de sujeitos falantes encarnados em diferentes corpos, que atuam como indicadores expressivos (CARDOSO FILHO; GUTMANN; AZEVEDO, 2017). Quando falamos do corpo midiático como dimensão da performance, nos referimos não apenas a um corpo biológico, de carne e osso, mas à construção simbólica de sujeitos, ou sujeitas, cujas formas de incorporação se valem de materialidades audiovisuais.

Neste estudo, o corpo se configura como dispositivo central de reflexão sobre o modo como o GNT constitui sentidos de feminilidades enquanto estratégia de interação com sua audiência. Ampara, portanto, a investigação sobre como, historicamente, o canal buscou se relacionar com seu público a partir da figura da "mulher contemporânea" permanentemente em disputa e que, pelas performances, se revela 
por formas expressivas diversas (texto verbal, vestimentas, enquadramentos de câmera, gestualidades e cenários) sempre postas em contexto. Por isso ressaltamos que, para a compreensão do modo como o canal constitui feminilidades a partir de certos corpos midiáticos, foram agregadas à análise considerações que se relacionam com questões de classe social, hábitos de consumo e estilo de vida.

\section{Entre rupturas e continuidades: feminilidades performadas pelo GNT}

"Mulher bonita é mulher que luta" nos diz a vinheta da programação do GNT.Doc para o mês da mulher em 2017 (GNT DOC, 2017), junto a imagens de mulheres de diferentes idades, nacionalidades e etnias, em manifestações de rua, com cartazes que fazem menção ao aborto e à liberdade feminina. Na peça exibida no mês de março de 2017 na grade do GNT, coexiste um movimento recente de visibilidade do canal: a associação com a imagem de uma mulher engajada na causa feminista e com um mundo globalizado por meio da veiculação de documentários, traço tradicional da emissora que já a definia em seu momento de estreia como "um canal só de informação" (VINHETA..., 2016).

O GNT acentua investimento na produção documental independente brasileira, com ênfase em temas do mundo urbano, a partir de 1996, ano em que surge o canal de notícias Globo News. A atualidade e o debate sobre os fatos são endossados como valores distintivos. Um de seus slogans mais conhecidos, veiculado entre 1996 e 2003, ratifica este lugar: "informação que forma opinião". Essa posição gerou prestígio, mas também era custosa. O processo de desvalorização do real, no final da década de 1990, quando a moeda deixa de ser equiparada ao dólar, atinge o mercado de TV por assinatura, pois as operadoras realizavam negociações, como o pagamento de canais estrangeiros e de equipamentos, com moeda estadunidense (ARAÚJO, 2014). É nesse período de crise que o GNT anuncia o interesse em se aproximar das mulheres, associando esse público a valores já estabelecidos: informação, atualidade, opinião, comportamento e urbanidade.

O canal mantém a relação com o jornalismo e com o documentário, reforçando enfoques dos temas atuais pela ideia de "serviço", mas produz um importante deslocamento em direção à interlocução com uma determinada construção de mulher brasileira. Em 2002, concretiza o plano de dar destaque às mulheres, ao lançar com ampla divulgação um programa de debates feminino que ocuparia o horário nobre de sua grade, o Saia Justa. A atração buscou se diferenciar da programação feminina presente na TV aberta, propondo-se a dialogar com uma "mulher moderna" por meio da apropriação de marcas jornalísticas e do debate dos fatos do noticiário econômico e político (CHAMUSCA, 2019). O sucesso ${ }^{4}$ do programa junto ao público e aos anunciantes incentivou a gestão do GNT a propor uma nova "cara" para o canal.

Investir no dito universo feminino, que tinha como núcleo programas como Superbonita, Saia Justa e GNT Fashion, mostrou-se um bom negócio porque, na mesma ocasião em que os canais pagos passaram a dar mais espaço a informes publicitários (ARAÚJO, 2014), o país vivia um momento em que o mercado voltava os olhos para o poder de compra da mulher. Matéria publicada pela IstoÉ, em 26 de junho de 2002, dá a dimensão desse contexto ao afirmar que "anúncios para produtos femininos começam a mudar seu enfoque para conquistar a mulher moderna e independente", ao passo em que também informa que o censo do IBGE de 2000 notificou "aumento de 37,6\% no número de mulheres responsáveis pelos lares em relação à última medição, em 1991” (A PROPAGANDA..., 2002).

Em setembro de 2003, quando a programação é renovada, a então diretora do GNT, Letícia Muhana, afirma: "Nós trabalhamos para esse público, da mulher que trabalha, cuida dos filhos e se cuida" (PESSINI, 2003). Ao caracterizar de tal maneira a sua interlocutora, o canal contribuiu para a naturalização da figura da mulher multitarefa. Trata-se de uma concepção que toma como resolvida a questão da desigualdade

4 Em matéria sobre o aniversário do programa, Padiglione (2003, p. T3) declara que ele tem "fôlego garantido por cinco patrocinadores" e que é “um dos programas mais assistidos do canal, alcançando médias mensais de 68,5 mil assinantes no horário nobre". 
de gênero e desobriga o restante da sociedade a se transformar para que as mulheres tenham seu espaço, já que as expectativas relacionadas a casamento, vida doméstica, filho e vaidade se associam àquelas vinculadas ao sucesso profissional e à independência financeira (CHAMUSCA, 2020).

Em alguma medida, essa audiência imaginada mantém traços de construções anteriores do canal. É com uma mulher cosmopolita, urbana e atenta ao noticiário que o GNT quer se relacionar. Ao mesmo tempo, ainda que tenha refutado a figura da dona de casa, ao lançar "uma programação com alma feminina", reitera associações entre feminilidade e domesticidade, uma vez que sua grade passa a ser ocupada por programas de decoração e culinária, além das atrações que já existiam sobre moda, beleza, saúde e comportamento. Havia, nesse contexto, uma recusa do feminismo, entendido como contrário ao exercício da feminilidade. Ao relatar quem deseja alcançar com o Saia Justa, Muhana diz: "A ideia é ter um reflexo da mulher contemporânea, sem ser feminista. Vamos falar de política, de cultura, mas também de batons" (JIMENEZ, 2002, p. T3). Para McRobbie (2004), no que chama de cultura popular pós-feminista, o feminismo é sutilmente apagado como ultrapassado na mídia por meio de uma noção de sucesso que convida as jovens a competirem na educação e no mercado de trabalho como se fizessem parte de uma nova meritocracia (MCROBBIE, 2004). O modo como a então gerente de marketing do canal, Carla Esteves, ressignifica a identidade visual lançada em 2008, no Dia Internacional da Mulher, reforça um traço de continuidade com a dinâmica de uma mídia pósfeminista quando afirma:

A grande inspiração para este on air foi justamente a mulher contemporânea. Ela faz mil coisas ao mesmo tempo e tem habilidade para ser, de forma plena, mãe, namorada, profissional, filha... Os papéis são vários e desempenhá-los com desenvoltura já faz parte da natureza desta mulher (GNT..., 2008).

Como também identificam as pesquisas realizadas por Chamusca (2020), Machado (2013) e Ponte (2009), as interações convocadas com o feminino são performadas no canal por um corpo midiático hegemônico, a mulher cis, branca, ocidental, urbana, cosmopolita e multitarefas, que se interessa por moda, maquiagem e qualidade de vida. A ênfase dada ao doméstico e à maternidade é associada ao êxito profissional, a exemplo da primeira série ficcional produzida pelo GNT em 2006, Mothern, protagonizada pela figura da mulher cuja experiência de ser mãe está inserida na dita modernidade. Assim, o GNT vai buscando um traço de distinção por meio do discurso de que representa a "mulher real", o que se explicita em 2011. Em entrevista ao portal R7, Muhana explica quem seria essa audiência imaginada: "Mulheres comuns mesmo, como eu, você" (SULINA, 2011).

Mas as transformações não foram tão significativas assim. A pesquisa realizada por Fabíola Machado (2013), que teve como recorte temporal o período de março de 2011 a agosto de 2012, corrobora essa percepção. A autora conclui que, por meio da produção de sentido do GNT, estabelecem-se como metas a magreza, a beleza, a juventude, a saúde, a harmonia doméstica, o equilíbrio nos relacionamentos, a boa imagem pessoal que, no limite, resume-se na aparência de ser ótima e feliz (MACHADO, 2013).

O próprio GNT, ao preparar um brand book para descrever as reformulações de 2011 e ao realizar o estudo "Mulheres em Evidência" em 2013, corrobora as percepções da pesquisadora. Na primeira publicação, o GNT diz querer dialogar com as mulheres de 25 a 45 anos, das classes A, B e C e destaca que "o grande foco porém são as mulheres de 30 anos, ativas, com valores familiares e que educam seus filhos de maneira consciente e responsável" (GNT, 2011). O estudo reforça esse vínculo com a mulher ativa economicamente e divide seu público de interesse em quatro perfis: Refinadas em tudo; Convictas; Minha imagem, Minha vida e Lar doce lar (GNT, 2013).

Um marco importante de deslocamento dessa construção de feminilidade foi a parceria firmada com a ONU Mulheres, em 2015, quando o GNT lança a campanha \#ElesporElas e assume o compromisso de conscientizar seu público sobre a importância da igualdade de direitos entre homens e mulheres. A partir 
de então, o lugar do feminino parece se deslocar para um corpo que se constitui mulher, também, pelas disputas em torno da igualdade de gêneros. Ou seja, os discursos que circulam no canal nos levam a uma constituição de mulher em que o mercado de trabalho e a beleza continuam sendo aspectos centrais. Porém, a mulher GNT também "se dá conta de que as exigências de se portar como alguém que consegue conciliar todas as tarefas são difíceis de serem mantidas e que a sua situação melhoraria se as estruturas ao seu redor se modificassem" (CHAMUSCA, 2020, p. 169). Um exemplo foi a campanha Rasgue o Verbo, realizada em 2016, que acionava performances de combate ao machismo através da interpelação por meio de frases cristalizadas no cotidiano brasileiro, exibidas nos intervalos da programação: "depois é estuprada e não sabe o motivo" e "a vocação da mulher é a família" (GNT, [2016]). Assim, o canal configura, pelo texto verbal, uma ação performática - enquanto crítica, desconstrução e reflexão - de recusa do sujeito ou sujeita machista.

Pelo que estamos denominando de performance televisiva - o modo como o canal interage com seu público a partir de figuras de si -, é possivel perceber articulações com outros corpos e encenações relacionados à paridade de gênero. Esse gesto é reforçado com a presença de corpos masculinos que evocam reconhecimento pela ideia de igualdade na relação com o "outro". Rodrigo Hilbert, que desde 2013 apresenta o programa de culinária Tempero de Família, é um exemplo. 0 apresentador, ex-modelo e ator de corpo jovem, musculoso e viril se constitui enquanto homem, esposo (da célebre apresentadora Fernanda Lima) e "pai de família" pela ênfase às habilidades de carpinteiro associada ao gosto pela culinária, pelas funções domésticas e pelo crochê.

Sobre esse aspecto, é importante ter em conta que a adesão por parte do canal a discursos feministas ocorre em um momento em que a sociedade brasileira vivencia um amplo debate público sobre gêneros e feminismos. Mais mulheres declaram-se adeptas do movimento, e o mercado, buscando alcançar esse perfil de consumidora, mostra-se atento às demandas por representatividade feminina e negra. Essa tendência vai sendo incorporada pelo GNT, mas dentro do quadro social/performático do corpo da mulher urbana, bem-sucedida, magra, cis e agora declaradamente feminista.

Um lugar importante para a observação desse movimento é o programa de debate Saia Justa. Ao longo da sua trajetória, o feminismo, que na sua estreia em 2002 foi refutado pela gestora do canal, constituiu pauta recorrente como "objeto" de debate. A reconfiguração do programa operada em 2017 diz respeito ao modo como o GNT abraça o discurso feminista e busca se mostrar antenado às demandas do feminismo negro. Passam a compor o elenco de apresentadoras, ao lado das veteranas Astrid Fontenelle e Mônica Martelli, a cantora e compositora Pitty, atuante em suas redes sociais nas questões de gênero, e a atriz negra Taís Araújo, engajada na luta antirracista.

Na edição de estreia da temporada de 2017, veiculada no Dia Internacional da Mulher, o gesto que sempre acompanhava o "salve" dito por Astrid para cumprimentar a audiência se encerra com o punho cerrado e envolto em um laço roxo, evocando um símbolo de luta e a cor do movimento feminista (Figura 1). Além de usar um batom com o mesmo tom, Pitty veste camisa preta com o símbolo do gênero feminino, sobreposto pelo desenho de uma mulher negra com os braços erguidos e as palavras More Power. A presença de um corpo negro no sofá que compõe o cenário, uma espécie de "sala de estar", é trazida à tona ao longo da edição, seja pela fala da própria Taís Araújo, pelas perguntas feitas pelas colegas ou pelo tweet de uma espectadora lido por Astrid: "Ótimo ver 3 brancas esperando 1 negra parar de falar, sem interrupção, só deixando ela falar, só ouvindo \#saiajustaaovivo" (INAUGURANDO..., 2017). No editorial, exibido logo na abertura do programa, o traço performático dessa nova conformação de apresentadoras é antecipado pela presença de Leila Diniz, Maria da Penha, Simone de Beauvoir e Angela Davis, cujos corpos aparecem articulados a imagens das marchas das mulheres que ocorriam naquela data em São Paulo, Nova York, Paris, Varsóvia e Washington. 


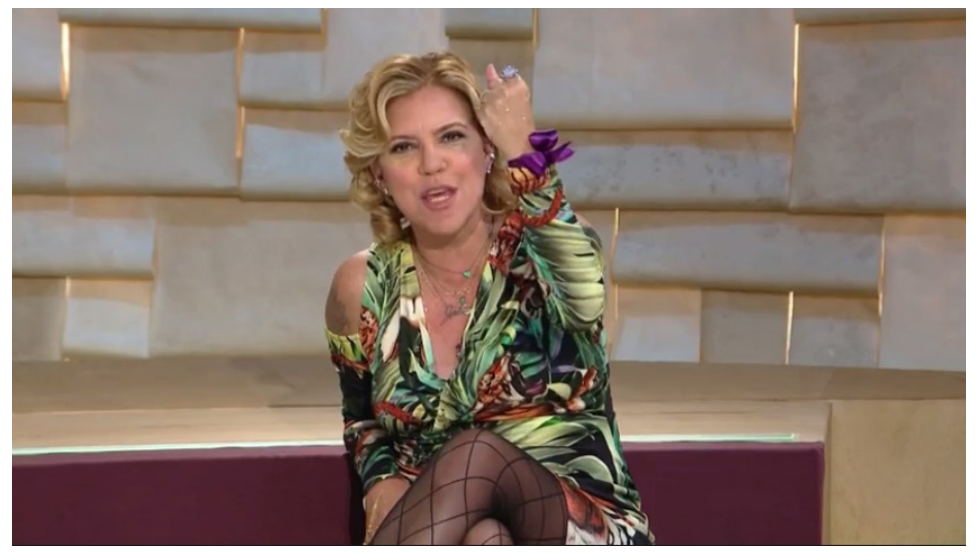

Figura 01: Gesto de Astrid no Saia Justa remete aos movimentos feministas

Fonte: Inaugurando... (2017).

Não só por meio do Saia Justa, mas também através de todas as peças analisadas aqui, em 2017, o GNT busca se associar à mulher que luta e é empoderada ${ }^{5}$ através de determinados corpos que também configuram, pelas suas performances, um lugar proposto para a interlocutora do canal. A vocação de construir figurações de si através de corpos cosmopolitas agora se atualiza pelas performances da mulher empoderada.

O site do GNT dá destaque à programação televisiva para o Dia Internacional da Mulher em 2017, reforçando esse lugar de feminilidade pelo sentido de empoderamento:

\begin{abstract}
Na segunda (06), estreia a nova temporada do 'Superbonita', que tem o empoderamento como palavra-chave e a apresentação poderosa da cantora e rapper, Karol Conka. Na quarta (08), começa também o novo 'Saia Justa', com um elenco $100 \%$ feminino e muito a dizer (GNT..., 2017).
\end{abstract}

O GNT também noticia sua participação no evento realizado pela ONU Mulheres, a Semana de Arte Eles por Elas, por meio da exibição e debate de um episódio da série Liberdade de Gênero, coprodução do GNT com a Copacabana Filmes sobre "histórias de vida de pessoas que não se identificam com o gênero designado para elas ao nascerem". (SOBRE..., [2016]).

É interessante perceber que o especial do GNT.Doc, com documentários exibidos nos domingos de março de 2017, com os temas "A sexualidade feminina", "SOS Aborto", "Angela Merkel" e "Mulheres fazendo história", não é citado na publicação de anúncio da nova programação. Também não foi mencionada no site a ação \#PoderdasMinas, ocorrida na Av. Paulista, com cobertura pelo Facebook, no dia de estreia do Saia Justa, em 2017. o programa transmitido ao vivo, apesar de exibir trechos da marcha realizada em São Paulo, não faz qualquer menção sobre o \#PoderdasMinas, promovido pelo canal no mesmo local e data.

Em sua página no Facebook, no período pesquisado, o GNT informou sobre as atrações da grade relativas ao Dia Internacional da Mulher, divulgou posts institucionais sobre a data, três deles relacionados à batalha \#PoderdasMinas, transmitiu ao vivo o evento no dia 8 de março, com duração de 45 minutos, e publicou um vídeo institucional intitulado "Dia da Mulher". O texto "Respeito às conquistas e à história

5 o conceito de empoderamento se refere ao processo pelo qual indivíduos e grupos sociais ampliam a capacidade de configurar suas vidas, a partir da compreensão de suas potencialidades e inserção na sociedade (FREIRE FILHO, 2006, p. 4). Isso implica consciência coletiva. Porém, ao ser utilizado no mainstream, não só desloca-se a ênfase para a autonomia individual, como é promovida articulação do "incremento do poder de compra de certos nichos de mercado com o poder político-social representado pela constituição de novas formas de subjetividade" (FREIRE FILHO, 2006, p. 4). 
de cada mulher é o que desejamos hoje e todos os dias \#DialnternacionalDaMulher" acompanha o vídeo protagonizado pela cantora Karol Conka, a atriz Mariana Xavier e a cartunista Laerte.

Com cabelos cor de rosa e camisa da banda de glam rock Twisted Sister com mangas cobertas por lantejoulas douradas, Karol aparece em um cenário urbano no vídeo, dentro de um carro e, em seguida, dançando na rua. Sua fala gira em torno da mulher negra reconhecer que tem poder e é linda. A atriz Mariana Xavier (Figura 2) é mostrada no contexto a partir do qual vem ganhando visibilidade na internet, a defesa de mulheres gordas serem livres para explorarem seus corpos na praia. Olhando para a câmera, afirma que não precisa achar ela bonita e pede respeito à sua história. Mas, diferentemente das fotos que a artista publica em seus perfis, nas quais aparece de corpo inteiro com lingerie ou biquíni, investe-se em planos próximos, que pouco mostram seu corpo, vestido com um maiô. Já Laerte, cartunista sessentona e ativista trans, aparece em um escritório, com uma estante de livros ao fundo, falando de como a luta das mulheres possibilitou aos homens encararem transformação na sua condição humana. A ambientação da cena reforça traços performáticos da fonte especializada cuja fala está em consonância com o discurso do GNT de que os homens devem ser implicados na busca pela igualdade de gênero. Assim, por essas performances, são acionadas figurações de mulheres negras, gordas, sessentonas e trans, mas sob um determinado quadro social/performático que oblitera possíveis marcas disruptivas em relação ao corpo exibido de modo predominante no canal.

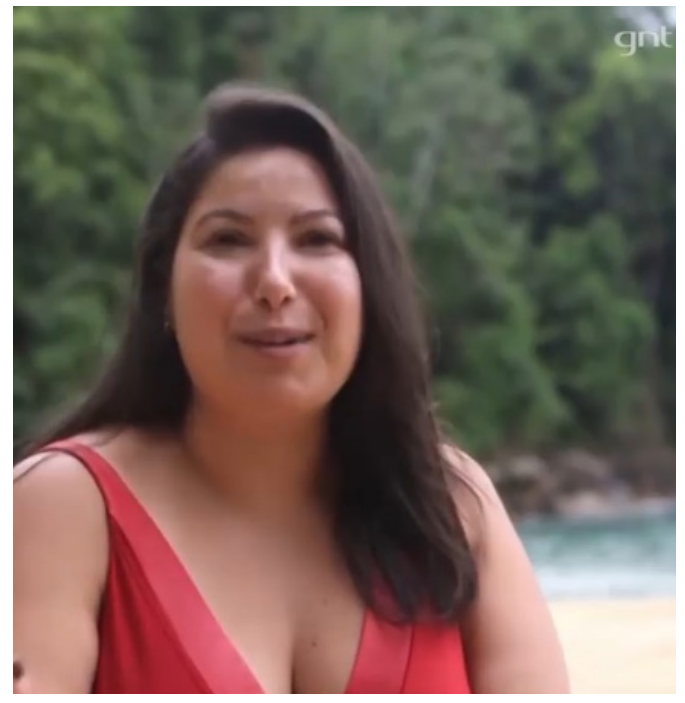

Figura 02: Mariana Xavier, enquadrada em plano médio, em vídeo institucional do GNT

Fonte: Dia... (2017)

Ao atualizar as suas vinhetas em 2008, o GNT já tinha tentado se colocar como lugar da diversidade, ainda que sem recorrer a esse termo. Ponte (2009) argumenta que o slogan "Você vê a diferença" remetia não só à distinção do canal perante a concorrência, mas também à pluralidade feminina. Porém, de acordo com a autora, se houve a intenção de representar mulheres brasileiras de diferentes perfis étnicos, ocorreu uma contradição por conta da escolha somente de mulheres magras com cerca de 20 anos, o que não contemplaria toda a faixa etária que o canal desejava alcançar (PONTE, 2009, p. 210).

Acrescentamos ainda que a diversidade étnica que se buscou imprimir à identidade visual não correspondia à realidade da programação, que em 2008 contava apenas com um corpo negro no elenco: Taís Araújo apresentando o Superbonita. Esse quadro não se mostra muito distinto na grade do GNT de 2017. Como destaque, o canal mantém Taís Araújo (Figura 3), agora como debatedora do Saia Justa, constituindo de modo enfático seu lugar político de mulher negra; e a rapper Karol Conka passa a comandar o programa Superbonita. 


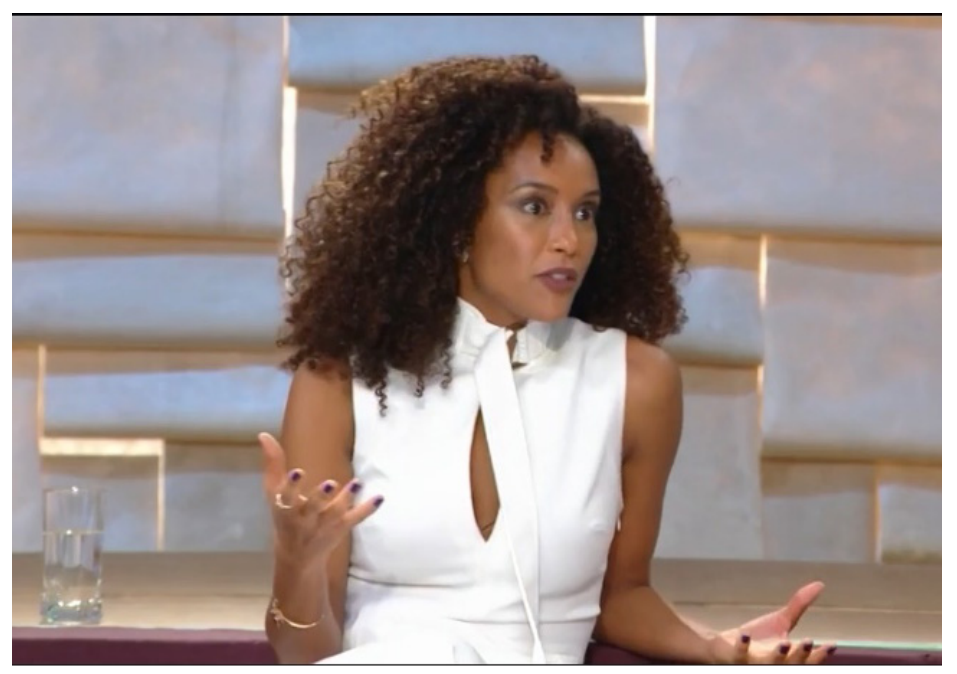

Figura 03: Estreia de Taís Araújo no Saia Justa em 2017.

Fonte: Inaugurando... (2017).

No entanto, quando direcionamos o olhar para as performances do feminino na ação \#PoderdasMinas, batalha de rap realizada por mulheres na Avenida Paulista, observamos que feminilidades outras despontam. $O$ texto de apresentação da live no Facebook reforça a proposta quando enfatiza "a união de mulheres de universos musicais diferentes para viver uma experiência inusitada" (PODER..., 2017). Participam da batalha, que teve como juíza MC Carol e como treinadora a rapper Gabi Nyarai, a cantora de pop e finalista do The Voice Brasil de 2015, Nikki, e três cantoras de rap: a paulistana com carreira mais longa no rap, Drik Barbosa, a carioca do Vidigal, que integra o grupo ABRONCA, Slick, e a santista Mariana Mello, em início de carreira.

O GNT busca corporificar a diversidade reunindo mulheres com performances distintas, evocando conexão com a periferia e a negritude a partir do rap, mas ainda reforçando, como traço de permanência, o cosmopolitismo e a urbanidade quando evidencia o espaço simbólico geográfico da Paulista. Entre as artistas, duas mulheres negras (uma com cabelos crespos na altura dos ombros e outra com longas tranças), uma loira e uma morena. Enquanto Mariana Mello e Slick compartilham um vestuário presente no universo do rap (calças largas com top ou body, boné, argolas grandes e correntes grossas no pescoço), os trajes de Nikki remetem ao pop (saltos altos, saia curta colorida) e Drik Barbosa se apresenta com um visual mais alternativo, combinando estampa geométrica e africana.

Desde 2003, o GNT vem ampliando os vínculos com o público jovem feminino, especialmente pela sua atuação na internet. Além das artistas convidadas terem cerca de 20 anos, a apresentação da batalha fica a cargo da jornalista Foquinha, que já atuou na revista Capricho e, desde 2014, tem um canal no YouTube de cultura pop e celebridades. Mas a afirmação do GNT nesta ação como espaço de encenações do feminismo é fundada na performance de MC Carol, que inicia e encerra a atividade, cantando a música "100\% feminista", lançada em outubro de 2016 e gravada em parceria com Karol Conka. MC Carol (Figura 4) aparece vestida com uma t-shirt com estampas de cédulas de dólares, shortinho verde musgo, tênis amarelo neon e um imponente relógio dourado. O corpo de formas volumosas, ressaltado pela camisa apertada, a voz firme e estridente e os gestos combativos presentificam a realidade que ela traz à tona por meio de versos diretos e próximos da mulher que vive nas periferias do país. 


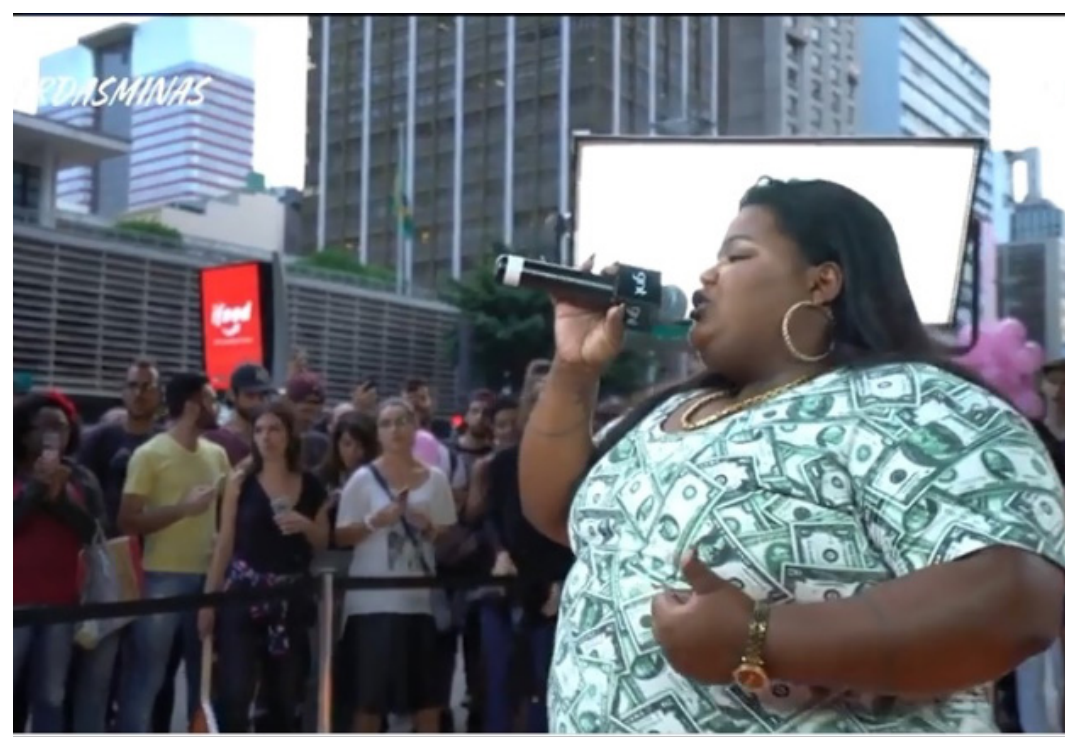

Figura 03: Estreia de Taís Araújo no Saia Justa em 2017.

Fonte: Inaugurando... (2017).

Se no Saia Justa a violência é pautada através de estatísticas, quando as apresentadoras informam em tom de voz que se assemelha às narrações jornalísticas que a "a cada 7 minutos é feita uma denúncia de violência contra a mulher", que "a cada 23 minutos morre um jovem negro" e que "a cada duas horas morre uma mulher violentada", na ação da Paulista, MC Carol canta em voz alta e firme: "Presenciei tudo isso dentro da minha família. Mulher com olho roxo, espancada todo dia. [...] Sou mulher independente não aceito opressão. Abaixa sua voz, abaixa sua mão". No que diz respeito à violência de gênero, temos um discurso que, na TV, ainda se faz enquanto "fato reportado" e nas redes sociais ensaia aproximações em direção ao vivido, nos termos de Diana Taylor (2013), ao incorporado. A construção da mulher violentada é preocupação da mulher politizada encarnada nos corpos de Taís, Pitty, Astrid e Mônica. No \#PoderdasMinas, é personificada por MC Carol.

E se MC Carol se desvia do padrão de magreza imposto aos corpos femininos, ela também exibe elementos associados à feminilidade do GNT - produção de cabelo e maquiagem, unhas compridas e pintadas. A treinadora da batalha Gabi Nyarai também se coloca como mulher periférica ("procurem saber, quebrada não é só violência, quebrada tem cultura, certo? Respeito à atividade periférica"), mas, diferentemente de MC Carol, sua atuação corporal recusa os códigos hegemônicos de feminilidade. Com uma camisa folgada e calça, nenhum acessório ou maquiagem e cabelo bem curto, ela canta suas rimas com os ombros ligeiramente curvados e balança os braços no ritmo da música com gestos firmes.

Além da diversidade, valores caros ao GNT, são tema dos quatro rounds da batalha ${ }^{6}$ a independência, beleza, poder e união, reforçados pelas imagens de abraços entre as cantoras, planos que enfatizam olhares cúmplices e expressões faciais de exaltação. Aliado a isso, divulgar a ação como uma experiência inusitada na vida das artistas, algo que fica visivel na transmissão ao vivo pelo Facebook, pois percebemos o embaraço da maioria delas para rimar de improviso, parece ser a forma encontrada pelo canal para demonstrar que toda mulher tem poder para fazer o que ela desejar. Essa escolha, porém, gera descontentamento em parte

6 As quatro participantes foram divididas em duplas. A cada 30 segundos, as cantoras tinham um tema para as rimas improvisadas. Ao final, MC Carol decidia quem era a vencedora do round a partir da reação do público. 
das seguidoras que, nos comentários, não só questionam a qualidade da batalha, como cobram a presença de mulheres que já fazem freestyle: "ué, só não tô vendo as MCs de batalha..."; "A maior batalha fake q cs respeita! Errou feio, errou bruto, errou rude GNT" (DIA..., 2017).

No YouTube, espaço em que o GNT vem consolidando produção própria, o canal publica um único vídeo da ação \#PoderdasMinas no dia 11 de março de 2017. 0 vídeo recorre à forma de videoclipe, com o rap de MC Carol conduzindo a abertura da montagem. O primeiro trecho acentua imagens aceleradas de carros no trânsito e pessoas atravessando uma faixa de pedestre. Caracteres no centro da tela identificam o tempo-espaço da ação: "São Paulo. Avenida Paulista. 8 de março". Ao som de "100\% feminista", cantada em alto volume por MC Carol, são apresentadas as mulheres participantes e trechos da batalha de rimas. 0 texto verbal inicial estampado na tela indexa sentido à cena: "Um encontro de mulheres. Feito por mulheres. Para Todas as Mulheres". Em seguida, a apresentadora Foquinha aparece falando: "somos negras, somos brancas, loiras, altas, baixas, magras, gordas, cacheadas, afros, todas nós somos maravilhosas na nossa diversidade" (ENCONTRO..., 2017).

O audiovisual evoca engajamento afetivo pela ênfase nos corpos que ali se assumem enquanto mulheres diversas em torno do sentido de união e empatia. Para usar um termo popular para parte dos discursos feministas, podemos dizer que as performances acionadas por aqueles corpos remetem ao sentido de sororidade. $\mathrm{O}$ tom das falas, a batida forte do rap, os discursos de empoderamento, os gestos que se impõem, os abraços, sorrisos e olhares cúmplices configuram uma cena de partilha assentada na diversidade enquanto marca de distinção e possivel reconhecimento por parte da comunidade do GNT nas redes sociais digitais.

\section{Performances de diversidade e suas ambiguidades}

A análise sobre os corpos que habitaram e orbitaram o GNT na semana do Dia Internacional da Mulher em 2017 são indícios do modo como o canal constitui performances de feminilidades assentadas no sentido de diversidade. Naquele ano, porém, ainda é possível detectar forte distinção em relação ao que ganha visibilidade na programação, no site e nas redes sociais. Na grade e no site, a passagem da data está associada à programação de linha e à produção e exibição de documentários. Identificamos a forma documental como marca de continuidade e lugar de prestígio para o GNT, tanto do ponto de vista da linguagem audiovisual como do modo como aborda a temática feminina. Já no Facebook e no YouTube, ganha maior visibilidade, como forma do canal celebrar "a mulher", o \#PoderdasMinas.

O GNT coloca mulheres negras em posição de destaque nos programas televisivos e nos produtos para a internet, mas não exatamente enquanto elemento de ruptura com o corpo hegemônico da emissora. Comportamentos associados a jovialidade, magreza, urbanidade, ao modo de se vestir fashion são reiterados pelas apresentadoras. Na grade, essas reiterações de feminilidades, quando incorporadas por mulheres negras, acentuam tanto a atitude atribuída ao visual descolado de Karol Conka no programa de beleza Superbonita, quanto o look mais clássico e sofisticado de Taís Araújo no programa de debate Saia Justa. Já nas ambiências digitais, o canal convoca outros corpos para celebrar o Dia Internacional da Mulher, corpos gordos, negros, idosos e trans. Mariana Xavier, no entanto, é percebida com enquadramento de câmera próximo ao ombro, o que dilui a potência da sua presença enquanto mulher gorda. Laerte assume posição de fonte especializada inserida num cenário "intelectualizado"; está ali num ambiente que privilegia seu lugar de autoridade, mas pouca ênfase é dada, pelo enquadramento e ambientação escolhidos pelo GNT, ao caráter geracional do seu corpo de mulher trans sessentona. Na batalha, percebemos maiores possibilidades de escapes para mulheres cujos corpos se expressam de outras maneiras, inclusive apropriando-se de códigos das masculinidades, mas a narrativa da diversidade é ancorada por um corpo jovem, branco, magro, de cabelos lisos, representado pela youtuber Foquinha. 
No ano seguinte, em 2018, a presença da cantora Gaby Amarantos, mulher negra, gorda, de origem periférica, com vestuários exuberantes, como mediadora do Saia Justa substituindo Taís Araújo, pode ser vista como um marco institucionalizador desse experimento, ainda que permaneça o enquadramento glamourizado do feminino. No episódio de sua estreia, ela é apresentada como mulher "gorda, mãe solteira, da periferia, do Norte", o que acentua a intenção do GNT em se apropriar do sentido de diversidade, uma vez que Taís Araújo é magra, sudestina, oriunda da classe média. Mas em 2019, o protagonismo dado à cantora pelo GNT é localizado no contexto digital. O canal demarca o Dia Internacional da Mulher no Facebook postando o trailer da série Travessia, criada pela programadora Globosat para contar a história de sete de suas apresentadoras. Escolhida para representar o GNT numa produção exclusiva para a internet, Gaby Amarantos surge na tela afirmando: "Eu tenho muito orgulho de ser uma cantora preta, de ser uma mulher preta, de ser preta".

Obviamente, a artista não foi a única mediadora gorda do canal. Podemos citar outros exemplos, como Barbara Gancia, que já apresentou o Saia Justa, a doceira Raiza Costa, que tem programa no canal desde 2015, a chef Carmem Virginia, que estreou como jurada do Cozinheiros em Ação em 2017, e a atriz Luana Xavier, que apresenta, desde 2020, o programa de turismo Viagem a Qualquer Custo. Corpos que tensionam questões sobre identidades de gênero também orbitam o canal. A série documental Liberdade de Gênero (2016-2017), por exemplo, apresentou histórias de vida de pessoas trans. Esses outros corpos, contudo, atuam mais para forjar sentido de diversidade do que enquanto traço da performance televisiva do canal.

No que diz respeito aos valores que o GNT busca convocar em 2017, entendemos que eles perpassam todos os ambientes analisados: a grade, o site, o perfil no Facebook e o canal no YouTube. Há recorrência da convocação do empoderamento e da beleza, assim como da diversidade e sororidade, além da reafirmação do vínculo com a mulher urbana. Pelas publicações que marcam a passagem da efeméride em 2018, 2019 e 2020, no Facebook e no YouTube, observamos que esses valores permanecem. A diversidade é figurada por meio de vídeos protagonizados por mulheres brancas, negras, jovens e de meia idade, magras, gordas, altas e baixas. A sororidade ganha ênfase, especificamente em 2018 e 2019, com os slogans "Juntas Somos Mais" e "Juntas Somos mais Fortes", assim como a significação do Dia Internacional da Mulher enquanto data que inspira luta (pela circulação de imagens de marchas feministas, depoimentos sobre desigualdade de gênero e divulgação do discurso feminista de Emma Watson, embaixadora da ONU Mulheres).

Tal convocação da diversidade pode ser analisada à luz das contribuições de Canclini (2009) sobre o tema. Para o autor, ao usarem o conceito de diversidade, políticas de pluralidade alicerçadas no respeito, por vezes, reforçam a segregação e uma percepção de aceitação do heterogêneo e não uma convivência em relações de negociação, conflito e empréstimos recíprocos. Nesse sentido, a análise aqui apresentada indica que o modo como o GNT forja figurações de si a partir desses corpos como estratégia de constituição de sua identidade, movimento aqui denominado de performance televisiva, convoca um sentido de diversidade palatável aos sujeitos cujas corporalidades estão assentadas em reiterações hegemônicas de feminilidades. E esse é um movimento perpassado por silenciamentos e ambiguidades.

Daí porque questionarmos, já no título do artigo, se essas mulheres estão mesmo juntas e misturadas. Ou seja, se essas performances remetem, pelas palavras de Canclini, a sociedades interculturais, nas quais ocorre efetivamente a mistura, o confronto, os intercâmbios entre grupos diversos, ou se simplesmente reforçam o que o autor chama de funis midiáticos, através dos quais "a variedade de estilos e formas de interação e convivência das culturas se reduz à medida que é capturada pelos meios" (CANCLINI, 2009, p. 146).

Pelo exposto, percebe-se que, na grade de programação do canal, o elenco de mulheres negras e gordas ainda é minoria e não há apresentadoras trans. Os deslocamentos observados colocam-se mais como estratégia de aproximação com o contemporâneo, via convocação de perspectivas feministas, de discursos de diversidade, igualdade de gênero e do sentido de sororidade, porém ainda pelo corpo 
hegemônico da mulher cis, heterossexual, jovem, urbana, magra, mãe, profissional, que se interessa por decoração, culinária, festas, moda e qualidade de vida. As mulheres lésbicas, as mulheres trans, as idosas, as mulheres da periferia, as vítimas de violência e tantas outras orbitam a esfera discursiva do canal, mas não corporificam como o GNT quer ser visto. Essas outras posições não se sustentam enquanto "eu" e nem enquanto "tu" na grade do GNT. Lá, elas ainda são "elas".

\section{Considerações finais}

Do ponto de vista teórico e metodológico, o uso aqui proposto da noção de performance, inspirado na formulação de performance televisiva (GUTMANN, 2015), parece-nos uma efetiva possibilidade de acessar as figurações de si de um canal pela análise dos corpos que ali constituem padrões de reiterações e possiveis rupturas, processo que se relaciona à experiência de consumo audiovisual. Os resultados analíticos dessa abordagem sustentam nosso argumento de que estratégias de comunicação de um canal se colocam como forma em ação. Ou seja, nas expressões materiais que adquirem sentidos quando em interação com possibilidades de leitura, repertórios e expectativas da audiência.

Ao mesmo tempo, entendemos que essas figurações, incorporadas nas e pelas performances das sujeitas e sujeitos que habitam e orbitam uma emissora, são formas históricas e culturais que constituem continuidades e transformações. Isso explica a importância de compreender historicamente os modos como o GNT se faz ver por associação com construções de feminilidades. Essa compreensão do "presente", enquanto temporalidades múltiplas, nos permite entender o canal e suas performances de feminilidades como um intenso e contínuo processo de formação cultural. Também nos habilita a perceber reiterações, rupturas e tendências, no marco dos produtos audiovisuais de 2017 analisados, que apontam para caminhos que o canal tomou nos anos seguintes. 


\section{Referências}

A PROPAGANDA é delas. Isto é, 26 jun. 2002. Disponível em: <https://istoe.com.br/26226 A+PROPAGANDA+E+DELAS/>. Acesso em: 29 jan. 2019.

ARAÚJO, M. 2000: A crise chegou e o sonho da TV paga virou pesadelo! TV Magazine, 4 nov. 2014. Disponível em: <https://www.tvmagazine.com.br/noticias/2000-a-crise-chegou-e-o-sonho-da-tv-paga-viroupesadelo,27269>. Acesso em: 29 jan. 2019.

BUTLER, Judith. Problemas de gênero. Feminismo e subversão da identidade. Rio de Janeiro: Civilização Brasileira, 2003.

CANCLINI, N. G. Consumidores e cidadãos: conflitos multiculturais da globalização. 8. ed. Rio de Janeiro: Editora UFRJ, 2015.

Diversidade e direitos na interculturalidade global. Observatório Itaú Cultural, São Paulo, n. 8, p. 145-152, abr./jul.2009.

CARDOSO FILHO, J.; GUTMANN, J. F. Performances como expressões da experiência estética: modos de apreensão e mecanismos operativos. Intexto, Porto Alegre, n. 47, p. 104-120, set./dez. 2019.

.; ______; AZEVEDO, R. J. Performances e memória em expressões televisivas. Revista Famecos, Porto Alegre, v. 24, n. 3, p. 1-17, set./dez. 2017.

CHAMUSCA, Tess. O GNT entra em uma Saia Justa: articulações entre identidade de marca e relações de gênero. Fronteiras, São Leopoldo, v. 21, n. 2, p. 79-91, mai./ago. 2019.

O GNT faz seu gênero? Uma abordagem cultural do canal televisivo e de suas relações com identidades de gênero. 2020. Tese (Doutorado) - Programa de Pós-Graduação em Comunicação e Cultura Contemporâneas, Universidade Federal da Bahia, Salvador, 2020.

DIA DA MULHER. [S. l.: s. n.], 2017. 1 vídeo (45 s.). Publicado pela fanpage GNT. Disponível em: <https://www. facebook.com/gnt/videos/1801533719872990/>. Acesso em: 15 jan. 2019.

DIA internacional da mulher. [S. l.: s. n.], 2017. 1 vídeo (22 s.). Disponivel em: <https://www.facebook.com/ gnt/videos/1799996556693373/>. Acesso em: 15 jan. 2019.

ELESPORELAS (HeforShe) - Spots Mídia: GNT Marcelo Tas e Bela Gil. [S. l.: s. n.], 2015. 1 vídeo (1 min.). Publicado pelo Canal ONU Mulheres Brasil. Disponivel em: <https://www.youtube.com/ watch?v=3ukIHRW6HGU>. Acesso em: 14 fev. 2019.

ENCONTRO de poder. [S. l.: s. n.], 2017. 1 vídeo (1 min. 52 s.). Publicado pelo canal GNT. Disponível em: <https://www.youtube.com/watch?v=t01JLY4g0zU>. Acesso em: 20 dez. 2018. 
FREIRE FILHO, J. Poder de compra: pós-feminismo e consumismo nas páginas da revista Capricho. In: ENCONTRO ANUAL DA COMPÓS, 15., 2006, Bauru. Anais... Bauru: Unesp, 2006.

GNT. Brand Book. Iussuu, 2011. Disponivel em: <https://issuu.com/marcioleite/docs/brandbook_gnt>. Acesso em: 25 fev. 2017.

Mulheres em evidência. GNTApps, 2013. Disponivel em: <http://gntapps.com.br/mulheresevidencia/pdf/Estudo_GNT.pdf>. Acesso em: 8 abr. 2021.

Rasgue o verbo. GNT, [2016]. Disponível em: <http://gnt.globo.com/especiais/eles-por-elas/ infograficos/rasgue-o-verbo.htm>. Acesso em 14 fev. 2019.

GNT DOC. [S. l.: s. n.], 2017. 1 vídeo (35 s.). Publicado pela fanpage GNT. Disponível em: <https://www. facebook.com/gnt/videos/1794713583888337/>. Acesso em: 7 fev. 2019.

GNT lança novo on air em março. Portal da propaganda, 6 mar. 2008. Disponivel em: <http://www. portaldapropaganda.com.br/portal/propaganda/2341>. Acesso em: 29 jan. 2019.

GNT participa da Semana de Artes Eles Por Elas em apoio à ONU Mulheres. GNT, Rio de Janeiro, 2 mar. 2017. Disponivel em: <http://gnt.globo.com/especiais/eles-por-elas/materias/gnt-participa-da-semana-deartes-eles-por-elas-em-apoio-onu-mulheres.htm>. Acesso em: 5 fev. 2019.

GOFFMAN, E. A representação do eu na vida cotidiana. Petrópolis: Editora Vozes. 10. ed, 2002.

GUTMANN, J. F. Sobre performance e historicidade: uma proposta de abordagem estética e cultural da MTV Brasil. In: ENCONTRO ANUAL DA COMPÓS, 24., 2015, Brasília. Anais... Belém: UnB, 2015.

INAUGURANDO a vida... [S. l.: s. n.], 2017. 1 vídeo (51 min. 35 s.). Publicado pelo GNT Play. Disponível em: <https://globosatplay.globo.com/gnt/v/5712077/>. Acesso em: 15 jan. 2019.

JIMENEZ, K. Novo programa do GNT tem humor e irreverência. 0 Estado de São Paulo, São Paulo, 14 abr. 2002. Telejornal, p. T3.

MACHADO, F. O. C. Seja ótima, seja feliz: Discurso, representação e subjetividade feminina no canal GNT. 2013. Tese (Doutorado em Comunicação Social) - Faculdade de Comunicação, Universidade de Brasília, Brasília, 2013.

MCROBBIE, A. Post-feminism and popular culture. Feminist Media Studies, v. 4, n. 3, p. 255-264, 2004.

PADIGLIONE, C. 'Saia Justa' faz festa de 1 ano com direito a platéia. O Estado de São Paulo, São Paulo, 13 abr. 2003. Telejornal, p. T3.

PESSINI, A. C. Mais jovem, urbano e feminino. Isto é gente, São Paulo, 22 set. 2003. Disponivel em: <https:// www.terra.com.br/istoegente/216/diversao_arte/tv_foco_mais_jovem_urbano_feminino.htm>. Acesso em: 15 maio 2017. 
PODER das minas ao vivo. [S. L.: s. n.], 2017. 1 vídeo (45 min. 52 s.). Publicado pela fanpage GNT. Disponível em: <https://www.facebook.com/gnt/videos/1801470439879318/>. Acesso em: 15 jan. 2019.

PONTE, R. F. d. Reflexões sobre o processo semiótico da identidade televisiva: o sonoro, o visual e o verbal nas vinhetas. 2009. Dissertação (Mestrado em Design) - Escola Superior de Desenho Industrial, Universidade do Estado do Rio de Janeiro, Rio de Janeiro, 2009.

SCHECHNER, R. Performance Studies: an introduction. New York: Routledge, 2006.

SOBRE o programa. GNT, Rio de Janeiro, [2016]. Disponivel em: <http://gnt.globo.com/programas/ liberdade-de-genero/>. Acesso em: 5 fev. 2019.

SULINA, V. GNT foca em "mulher real" em sua nova programação. R7 Entretenimento, 15 mar. 2011. Disponível em: <http://entretenimento.r7.com/famosos-e-tv/noticias/gnt-foca-em-mulher-real-em-suanova-programacao-20110315.html>. Acesso em: 14 fev. 2019.

TAYLOR, Diana. $\mathbf{0}$ arquivo e o repertório: performance e memória cultural nas américas. Belo Horizonte: Ed. UFMG, 2013.

VINHETA antiga do canal GNT (1991). [S. l.: s. n.], 2016. 1 vídeo (20 s.). Publicado pelo Canal Fita VT. Disponivel em: <https://www.youtube.com/watch?v=RmX8Ycf35UY>. Acesso em: 14 fev. 2019.

WILLIAMS, R. Marxismo e Literatura. Rio de Janeiro: Jorge Zahar, 1979.

ZUMTHOR, P. Performance, recepção e leitura. São Paulo: Cosac Naify, 2007. 


\section{Informações para textos em coautoria}

\section{Concepção e desenho do estudo}

Juliana Freire Gutmann e Tess Chamusca

Aquisição, análise ou interpretação dos dados

Juliana Freire Gutmann e Tess Chamusca

\section{Redação do manuscrito}

Juliana Freire Gutmann e Tess Chamusca

\section{Revisão crítica do conteúdo intelectual}

Juliana Freire Gutmann e Tess Chamusca

\section{Informações sobre 0 artigo}

\section{Resultado de projeto de pesquisa, de dissertação, tese}

0 artigo é resultado da tese de doutorado "O GNT faz seu gênero? Uma abordagem cultural do canal televisivo e de suas relações com identidades de gênero" e da pesquisa "Performance como dimensão de apreensão da cultura audiovisual nas ambiências digitais" (Universal 2018/2022).

\section{Fontes de financiamento}

Pesquisa de doutorado - Bolsa Capes. Projeto de pesquisa - Cnpq/ Chamada MCTIC/CNPq № 28/2018 - Projeto 426362/2018-7.

\section{Considerações éticas}

Não se aplica.

Declaração de conflito de interesses

Não se aplica.

\section{Apresentação anterior}

27o Encontro Anual da Compós, Porto Alegre, 2019. (No encontro foi apresentada uma versão ainda preliminar dos resultados de pesquisa).

\section{Agradecimentos/Contribuições adicionais}

Não se aplica. 